\title{
Performance Analysis of The Effect on Insertion Guide Vanes For Rectangular Elbow $900^{\circ}$ Cross Section
}

\author{
Setyo Nugroho, Achmad Arifudin Hidayatulloh \\ Power Plant Technology, Electronic Engineering Polytechnic Institute of Surabaya \\ Jalan Raya ITS Sukolilo, Surabaya 60111 \\ setyo@pens.ac.id
}

\begin{abstract}
The use of elbow or curved pipe in the installation of piping has a loss of pressure (pressure drop) which could lead the power of pump that drive the fluid and decrease the energy efficiency of the system. The pressure drop is caused by the curved shape of the elbow that cause pressure on the outer wall (outter) larger and blocking off the pace of the fluid, and flow pressure losses caused by friction, flow separation and secondary flow. A method that can be used to reduce flow separation and pressure loss in the elbow is by the insertion guide vane. The test model in the form of rectangular elbow $90^{\circ}$ with a radius ratio $\left(\mathrm{r}_{\mathrm{c}} / \mathrm{D}_{\mathrm{h}}\right)=1.1249$ without using a guide vane and number of guide vane insertion one until three guide vanes. With Reynolds number $\mathrm{Re}_{\mathrm{Dh}} \approx 8.6 \times 10^{4}$. The velocity inlet is uniform, the measured variable is static pressure. Static pressure was measured using an inclined manometer. With variation the number of guide vane gives a more effect on the value of pressure drop, the largest pressure drop until $123.35 \%$ compared to that without guide vane. The velocity distribution profile on the outlet side becomes more uniform. The magnitude of this pressure drop occurs as a result of the increased flow friction and its secondary flow become smaller.
\end{abstract}

Keywords: Rectangular elbow $90^{\circ}$, guide vane, pressure drop, secondary flow

\section{INTRODUCTION}

Bended pipe or curved pipe or elbow is one of the components in a piping installation, where this pipe - shaped turn with the shape and angle of curvature that varies in order to simplify a system installation. In fluid mechanics use of curved pipe will also cause a loss of pressure (pressure drop) larger than compared with a straight pipe in equal length. In general, this pressure drop caused by friction (friction loss), flow separation (separation loss) and also a secondary flow phenomena (secondary flow). Friction loss occurs due to the friction between the fluid with the wall test model. The occurrence of flow separation is caused by the inability of a flow 
against adverse pressure gradient (APG) so that the flow will partially detached and reversed direction from the main flow to form a vortex. While the secondary flow is due to an imbalance between the pressure and the centrifugal force on the outside wall of the channel at the time of passing the turn. The existence of this centrifugal force causes the particles of the fluid in the inner side of the wall will be accelerated and will lead to a block area. Therefore, flow separation and secondary flow gives a great influence in the cause of the pressure drop. The pressure drop will cause the larger power consumption in a pump. This will lead to decreasing of energy efficiency of the system, especially in power plant system. The research about separation and pressure distribution in elbow was studied by Cheng [1], Kim and Pattel [3], and Miller [4]

Based on journal Haskew [2] about the research in perfomance evaluation of vaned pipe bend in turbulent flow of liquid propellants. This study propose using guide vanes on the side of the elbow to minimize pressure losses in the pipe installation, reducing the phenomenon of secondary flow and see the development of the formation of velocity distribution profile. Increasing the number of blades steering will affect the performance of this elbow. By doing variations of the addition of the steering vane will be known the value of the loss of pressure, the pressure distribution and velocity profile

\section{RELATED WORKS}

There are many methods to learn about this research issue. The main issue that usually observed are about pressure distribution along the streamline, the strength of secondary flow, and the streamline itself. The streamline will determine how the pressure and velocity vectors behave. To know about the streamline could use Computational Fluid Dynamic simulation, using flow visualization with smoling wind tunnel, or using image processing with Particle Image Velocimetry device. This research will be conducted with CFD simulation, and using pressure tap along the elbow.

\section{Internal Flow in an Elbow}

Cheng (1994) illustrated that the streamline pattern inside an elbow as shown in Figure 1. There is significant pressure difference between inner and outter section. The existence of this pressure difference will cause flow separation in both section so that will reduce the effective cross section 


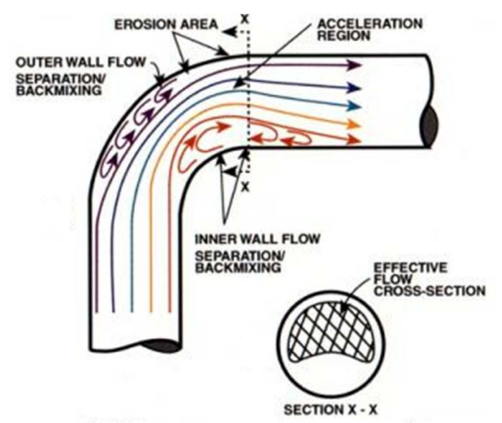

Figure 1. Flow separation inside an elbow Cheng (1994)

Cheng disovered this phenomenon by using computational simulation with turbulence modelling and viscous dissipation energy. And this research will also using those kind of method.

\section{Secondary Flow}

Miller (1990) stated that if the fluids flow through an elbow will experience centrifugal force. Figure 2 explain that the centrifugal force acting in outter section is larger than in inner section, so the flow reaction due this force will become larger as well by increasing the pressure. So there will be a flow from the outter to the inner section that will influence the velocity profile in certain cross section.

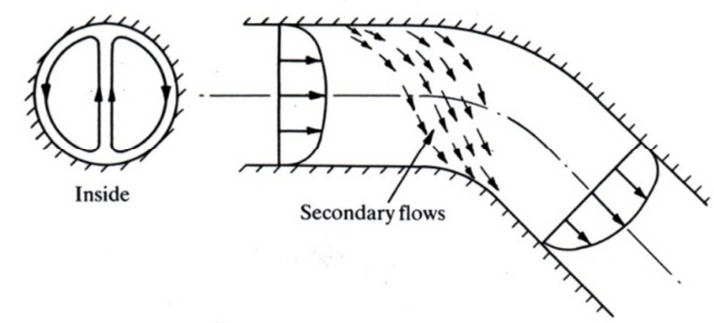

Figure 2. Secondary Flow Miller (1990)

An existence of secondary flow is avoided in piping system because a laminar and uniform flow is desired in suction side of the pump in order to increase the work efficiency of the pump.

\section{Pressure Distribution along Inner and Outter of the Elbow}

Kim dan patel (1994) researched that pressure coefficient (Cp) has a negative value in inner section and positive value in outter section, this is explain the secondary flow as stated by Miller (1990). This pressure difference will lead to flow separation and vortex flow in the corner of the cross section 


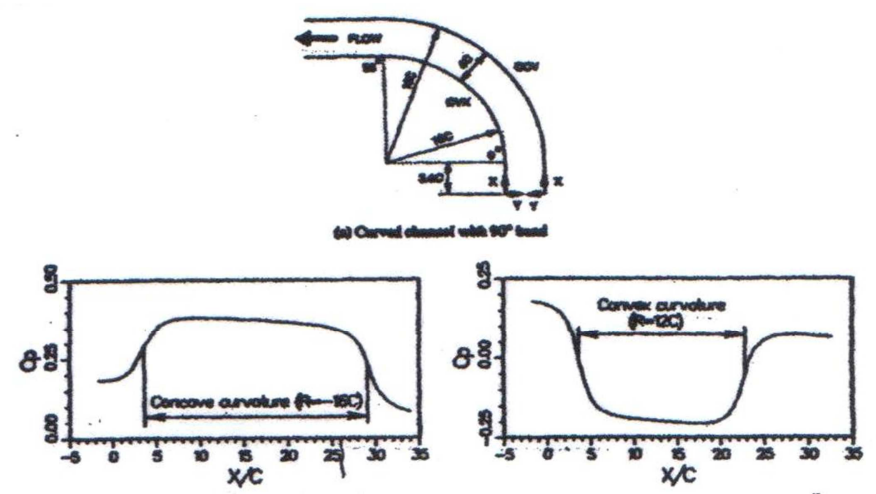

Figure 3.Pressure Coefficient along inner and outter section Kim and Patel (1994)

\section{EXPERIMENTAL AND NUMERICAL METHOD}

This research will use two methods, which are; numerically by using CFD simulation to know about the streamline, secondary flow, pressure and velocity distribution along the streamline. The second method is using pressure tap along the streamline to measure the static pressure distribution and know the pressure loss between inlet and outlet experimentally.

The experimental and numerical was perfomed in this research. Experiment was conducted in Fluid Mechanics Laboratory, and numerical study was conducted in Computer Laboratory, Power generation system, Electronic Engineering Polytechnic Institute of Surabaya.

\section{Experimental Study}

Main component in this experimental set-up is a rectangular elbow $90^{\circ}$ without and with guide vanes. Air flow induced fan and the flow passed through straight channel and entering nozzle for increase the velocty until 20 $\mathrm{m} / \mathrm{s}$. in Figure 1 show the main component rectangular elbow $90^{\circ}$. The inner radius $\left(\mathrm{r}_{\mathrm{i}}\right)$ of the elbow is $50 \mathrm{~mm}$, while the outer radius $\left(\mathrm{r}_{\mathrm{o}}\right)$ is $100 \mathrm{~mm}$. The elbow cross section is rectangular with $100 \mathrm{~mm}$ width and $50 \mathrm{~mm}$ height. With hidrolic diameter is $66.67 \mathrm{~mm}$. length upstream is $92 \mathrm{~mm}$, length of downstream is $98 \mathrm{~mm}$. The length from inlet to outlet for inner $\left(\mathrm{l}_{\mathrm{i}}\right)$ is 268,54 and the length from inlet to outlet for outer $\left(l_{0}\right)$ is 347.08 .

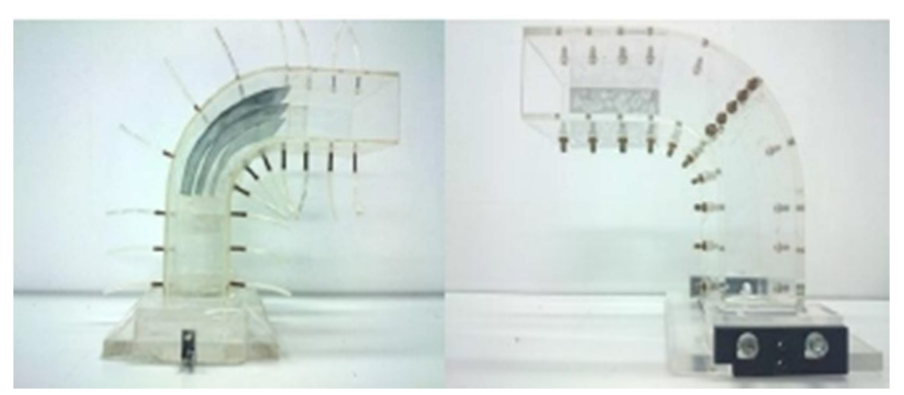

(a)

(b)

Figure 4. Rectangular elbow $90^{\circ}$ (a) with three guide vanes and (b) without guide vanes 
Pressure static measurement were conducted using inclined manometer filled with water. The manometer connected to wall pressure tabs located of the test section. For the purpose of wall static distribution, as 11 and 11 static pressure tabs located on the inner side of the wall elbow and outer side of the wall elbow. In table 1 represent for experimental study geometry

Table 1. Rectangular elbow's geometry

\begin{tabular}{|c|c|c|l|}
\hline Section & Inner $(\mathbf{l i})(\mathbf{m m})$ & Outter $\left(\mathbf{l}_{\mathbf{o}}\right)(\mathbf{m m})$ & $\mathbf{X}_{\mathbf{c}} / \mathbf{D h}_{\mathbf{h}}$ \\
\hline Inlet & 0 & 0 & 0 \\
\hline 1 & 20 & 20 & 0.2999 \\
\hline 2 & 51 & 51 & 0.7646 \\
\hline 3 & 82 & 82 & 1.2294 \\
\hline 4 & 109.45 & 126.9 & 1.7718 \\
\hline 5 & 131.27 & 170.54 & 2.2624 \\
\hline 6 & 153.54 & 214.17 & 2.7531 \\
\hline 7 & 179.54 & 258.08 & 3.2805 \\
\hline 8 & 203.54 & 282.08 & 3.6403 \\
\hline 9 & 228.54 & 307.08 & 4.0151 \\
\hline 10 & 253.54 & 332.08 & 4.3900 \\
\hline Outlet & 268.54 & 347.08 & 4.6148 \\
\hline
\end{tabular}

\section{Numerical Study}

In this numerical study, Computinal Fluid Dynamics (CFD) software were utilized. Common steps in numerical study: pre-processing, solving, and post processing. a domain fluid for Fluent represented in figure 5, meshing, set-up the turbulence model, set input for the model, and set the operating condition. Solving step is. Iterations up to minimal error $10^{-6}$, and final step post-processing is, velocity and pressure distribution, pathline explained in Table 2.

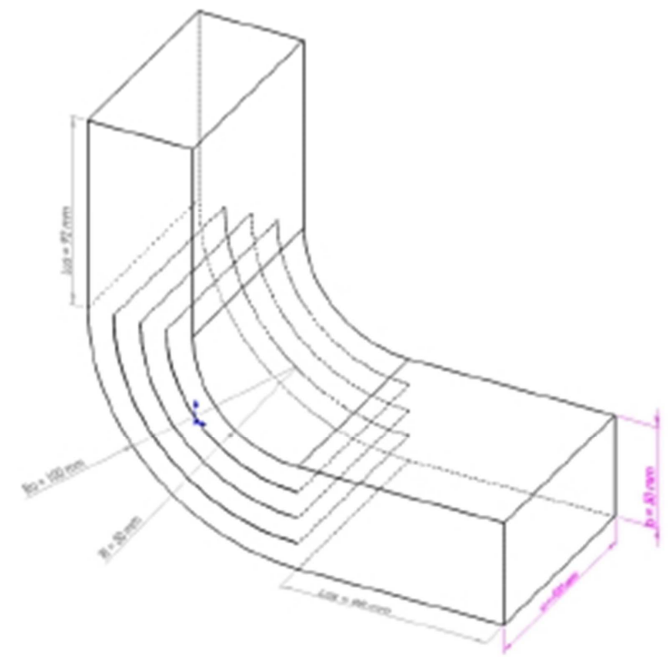

Figure 5. Rectangular elbow $90^{\circ}$ design with insertion three guide vanes 
Table 2. The Numerical Study Properties

\begin{tabular}{|c|c|}
\hline Step & Detail \\
\hline Modeler & Solidwork 2012 \\
\hline Meshing & ANSYS Meshing \\
\hline Model & $\begin{array}{l}\text { Double Precision; Reynolds Stress Model } \\
(R S M)\end{array}$ \\
\hline Material & air: $\rho=1.19 \mathrm{~kg} / \mathrm{m} ; \mu=1^{3}, 84 \times 10^{-5} \mathrm{~N}^{2} \mathrm{~s} / \mathrm{m}$ \\
\hline $\begin{array}{l}\text { Operating } \\
\text { condition }\end{array}$ & $\begin{array}{l}\sim 101325 \text { Pascal } \\
\text { Gravity y }=-9,81 \mathrm{~m} / \mathrm{s}\end{array}$ \\
\hline $\begin{array}{l}\text { Boundary- } \\
\text { Condition- }\end{array}$ & $\begin{array}{l}\text { Velocity Inlet: } U_{\text {ref }}=20 \mathrm{~m} / \mathrm{s} \\
\text { Pressure Outlet: Pressure gauge }=0 \text { pascal }\end{array}$ \\
\hline $\begin{array}{l}\text { Solution } \\
\text { Methods }\end{array}$ & $\begin{array}{l}\text { Scheme : Coupled } \\
\text { Gradient : Least square cell base } \\
\text { Pressure : Standard } \\
\text { Momentum : Second Order Upwind } \\
\text { Spesific Dissipation Rate : Second Order } \\
\text { Upwind } \\
\text { Reynold Stresses: Second Order Upwind }\end{array}$ \\
\hline Monitor & Convergence Criteria : $10^{-6}$ \\
\hline
\end{tabular}

\section{RESULTS AND DISCUSSION \\ Pressure Coefficient (Cp) and Pressure Drop}

Pressure coefficient ( $\mathrm{Cp}$ ) is plotted as a function of the number of guide vanes, for both experimental and numerical result. Figure 6(a) shows the distribusion $\mathrm{Cp}$ along the wall of the test section for the elbow without guide vane, while figure 6(b), 6(c), and 6(d) show the distribution of $\mathrm{Cp}$ for the elbow with one, two,and three guide vanes, respectively. In figure 7 it shown that there is a significant different in pressure coefficient between inner and outer elbow wall. In inner wall has a negatif pressure coefficient caused the sentrifugal force make a particle pressure to the outer side. In inner side the velocity has increase caused the pressure in inner side was a negatif pressure gradient. And in outer side the pressure was increase caused the outer side pressure have a favorable pressure gradient and make a velocity in outer side will be decrease. When negative pressure gradient and going towards positive pressure gradient will potentially can lead to separation and formation of secondary flow if the flow does not have enough momentum to overcome the existing obstacle. 


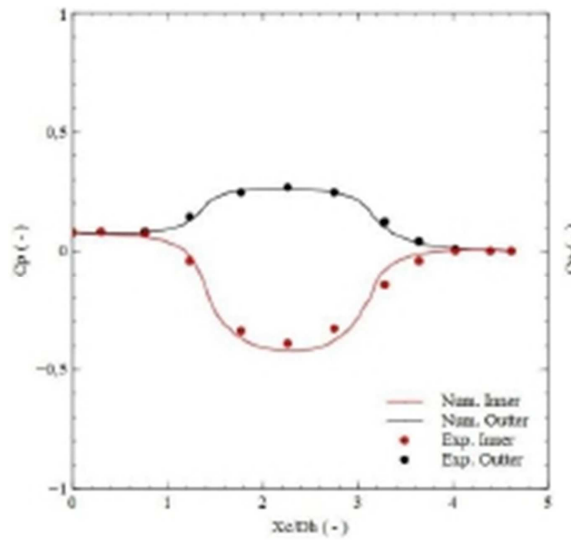

(a)

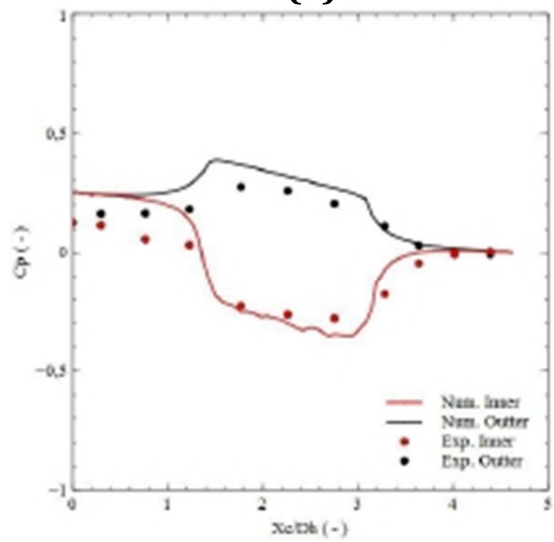

(c)

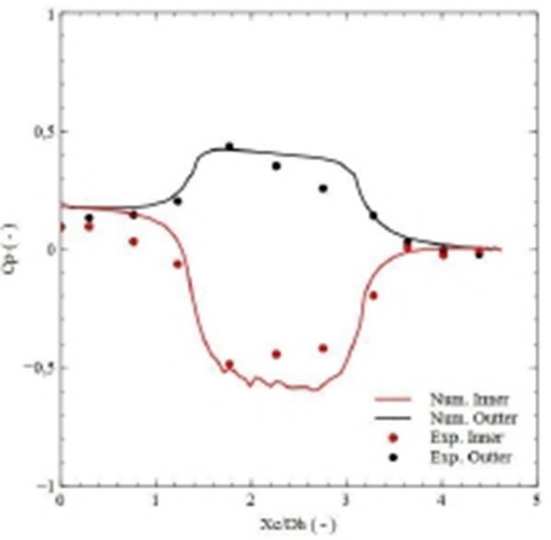

(b)

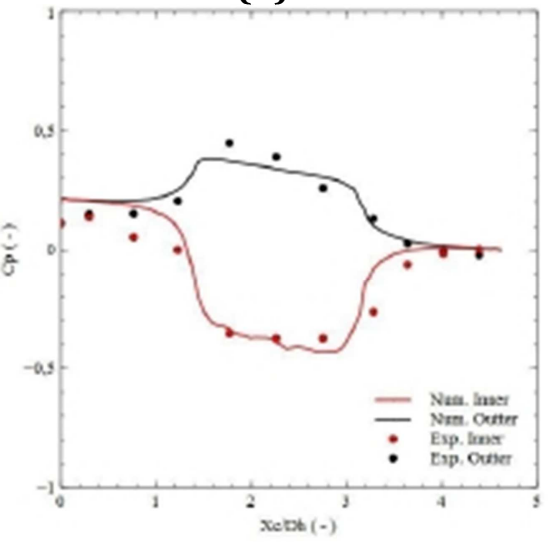

(d)

Figure 6. Cp distribution in elbow (a) without guide vane, (b) one guide vane, (c) two guide vanes, $(d)$ three guide vanes

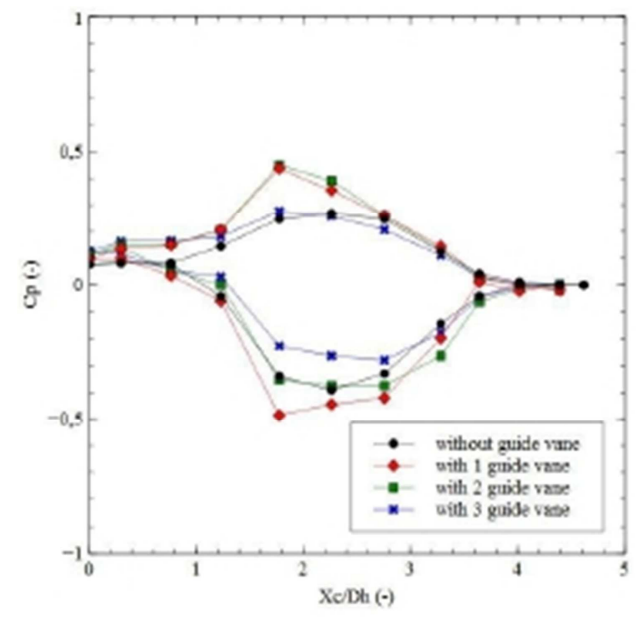

Figure 7. Experimental study $\mathrm{Cp}$ distribution in all variation

For the $\mathrm{Cp}$ values between the inner and outer sides of the greatest variation occurs in the guide vane where the position $X_{c} / D_{h}=1.773 C_{p}$ values obtained them are -0.485 and 0.435 , indirectly, in one guide vane has 
indicated that the pressure drop flow will also increase. With increasing number of guide vane spacing between $\mathrm{Cp}$ values has narrowed, as seen on the graph for a variation of three guide vane which at the same position, namely in the $X_{c} / D_{h}=1.773 C_{p}$ values obtained them are -0.226 and 0.275 , this indicated elbow with three guide vane can reduce the pressure drop and the secondary value of the flow.

Table 3. The effect of guide vane insertion on pressure drop

\begin{tabular}{|c|c|c|c|c|c|}
\hline \multirow{2}{*}{ Variation } & \multicolumn{2}{|c|}{$\Delta \mathrm{p}(\mathrm{Pa})$ (inlet-outlet) } & \multicolumn{2}{|c|}{$\% \Delta \mathrm{p}(\%)$ (inlet-outlet) } & $\begin{array}{c}\text { Pressure } \\
\text { Error } \\
(\%)\end{array}$ \\
\cline { 2 - 6 } & $\begin{array}{c}\text { Eksperiment } \\
(\mathrm{Pa})\end{array}$ & $\begin{array}{c}\text { Numeric } \\
(\mathrm{pa})\end{array}$ & $\begin{array}{c}\% \Delta \mathrm{p} \\
(\text { Eksperiment })\end{array}$ & $\begin{array}{c}\% \mathrm{p} \\
(\text { Numeric })\end{array}$ & $\begin{array}{c}\text { Error } \\
(\%)\end{array}$ \\
\hline $\begin{array}{c}\text { No guide } \\
\text { vane }\end{array}$ & 13.45 & 17.90 & - & - & 24.86 \\
\hline $\begin{array}{c}\text { One } \\
\text { guide } \\
\text { vane }\end{array}$ & 25.67 & 43.61 & 90.85 & 143.63 & 41.14 \\
\hline $\begin{array}{c}\text { Two } \\
\text { guide } \\
\text { vanes }\end{array}$ & 29.09 & 51.08 & 116.28 & 185.36 & 43.05 \\
\hline $\begin{array}{c}\text { Three } \\
\text { guide } \\
\text { vane }\end{array}$ & 30.31 & 59.99 & 125.35 & 235.14 & 49.47 \\
\hline
\end{tabular}

Table 3 shows pressure drop at each variation of the additional guide vane experimentally and numerically. In table 3 can be seen the value of each additional pressure drop guide vane growing and for experiments on three guide vane $\Delta \mathrm{p}$ value increased by $123.35 \%$ and for numerical studies $\Delta \mathrm{p}$ value increased by $235.14 \%$. The addition of the guide vane numbers in the same Reynolds numbers, making the value of growing pressure drop. This is because the increasing number of guide vane then the effect of friction that occurs also happens to be growing on the wall elbow and guide vane. The difference between the value of experimental studies and numerical study is due to various factors such as the relevant roughness on elbow wall and solid wall surface on the guide vane.

\section{Velocity Distribution Profile}

Velocity distribution profile at the outlet of the elbow are shown in Figure 7. In Figure 7(a) shown the velocity profile for elbow without guide vane. Velocity distribution was presented with a form of dimensionless velocity $\mathrm{u} / \mathrm{U}$ function of dimensionless position $(\mathrm{r} / \mathrm{b})$, where $\mathrm{u}$ is the local velocity and $U$ is the maximum speed obtained on the section, $r / b=-1$ is the inner side and the $r / b=1$ is the outer. 


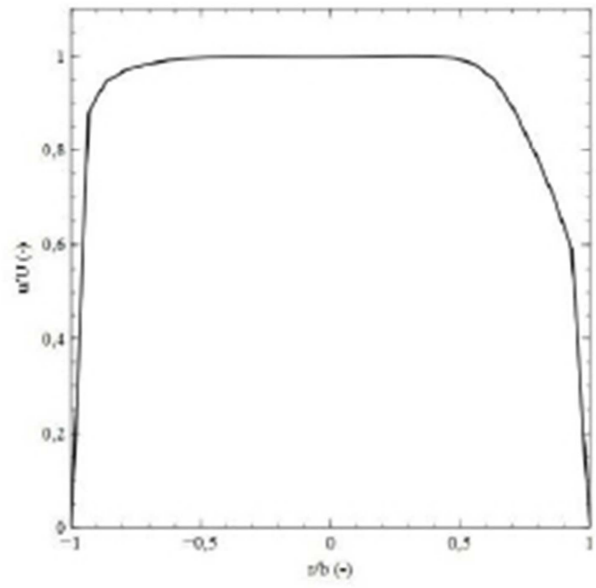

(a)

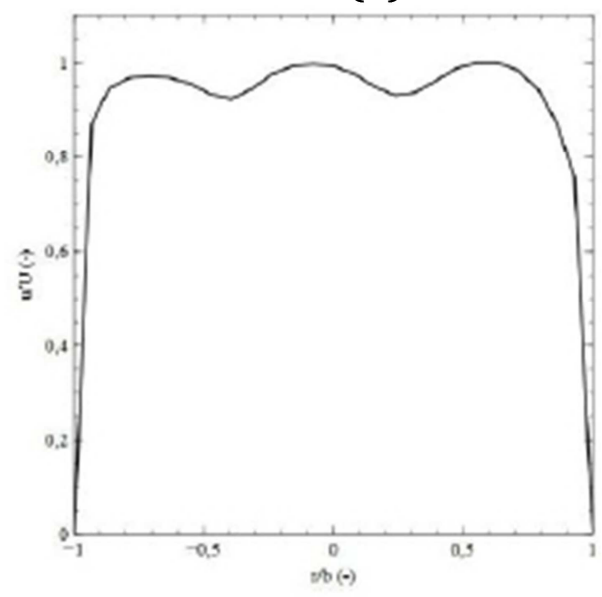

(c)

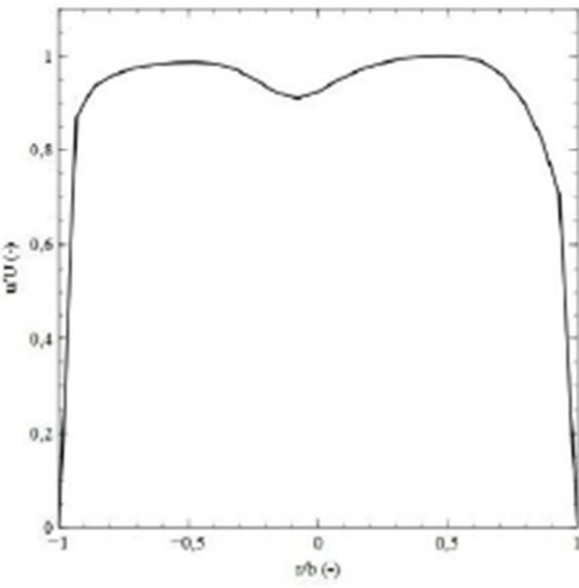

(b)

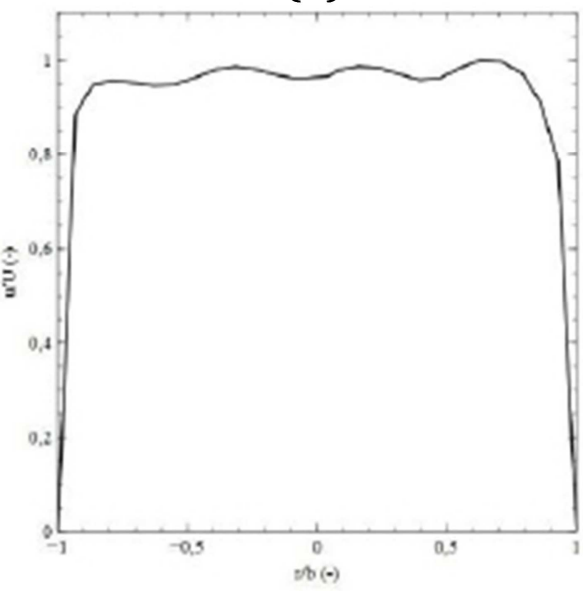

(d)

Figure 7. Velocity distribuition profile in elbow (a) without guide vane, (b) one guide vane, (c) two guide vanes, (d) three guide vanes

The distribution of the velocity profile is only viewed from the side of the outlet because the outlet side of it can be seen the effect of the existence of guide vane of the velocity distribution profile. At Figure 7(b) the picture we can see the velocity profile for each additional variation guide vane. When the addition of the guide vane profile was similar as the velocity profile at the outlet guide vane without any variation but at the centerline where $\mathrm{r} / \mathrm{b}=0$ there are bend because of the influence of the guide vane. At this point the existence of one guide vane is still enough to affect the shape of the velocity profile at the outlet side. As for the velocity profile is almost towards uniform can be seen in Figure $7(d)$, is seen in profile more flat elbow velocity when the addition of three guide vane than the elbow without guide vane. With these differences can provide information on the effect of the addition of three guide vane add greater momentum to minimize secondary fluid flow to the profiles on a flow velocity distribution in the elbow. 


\section{Secondary Flow}

In Figure 8 shows that the secondary flow phenomenon in rectangular elbow $90^{\circ}$. The formation of secondary flow is quite significant in reducing the flow velocity. Secondary flow also causes blockage of the main flow. Over this distance increases in the downstream area of the elbow, rotating fluid flow is greater because ( ${ }^{-}$Inlet e longer distance will result in greater friction by the fluid.
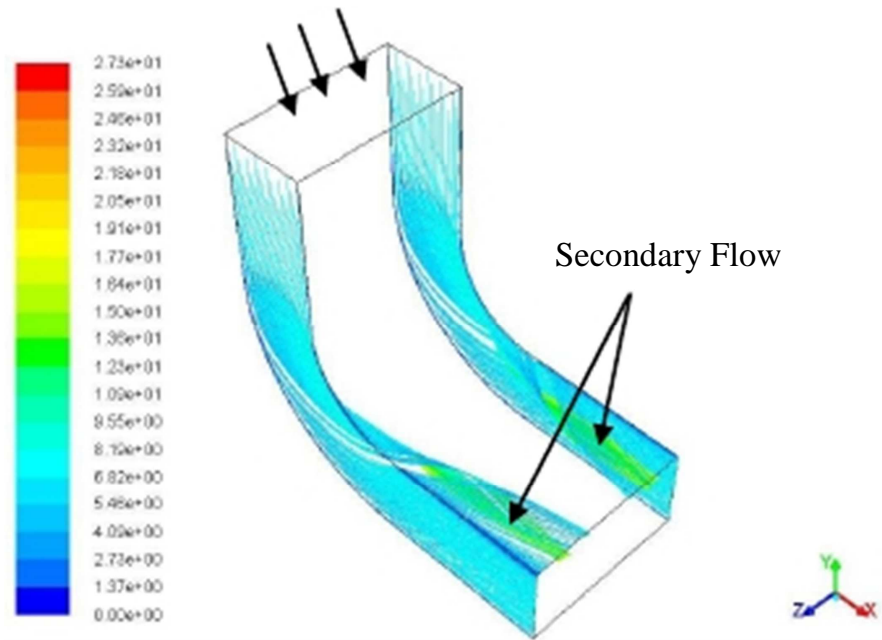

Figure 8. Pathline in wall elbow without guide vane

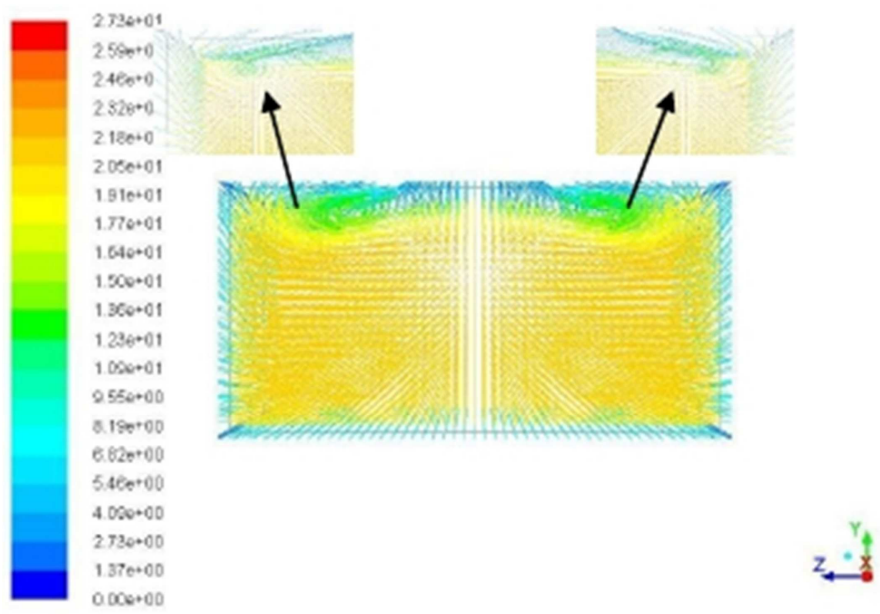

Figure 9. Vortex at outlet elbow without guide vane

The formation of vortex in figure 9 is generated by the movement of the combination of the elements of the fluid flow inside the boundary layer so that the fluid element residing in the area of translational motion also perform a rotational movement. The rotational movement is due to the effects of viscosity and velocity gradient. The farther the distance of the fluid in the inner wall of this will make the enlarged vortex. So with this case the secondary flow and the vortex flow, it can lead to pressure drop and reduce the effective flow area so that clogging or blockage effect area. 
At Figure 10 the picture also shows pathline formation of secondary flow on elbow wall. The velocity more is gradually increasing is shown in yellow pathline line, in addition to the formation of the flow of play from the secondary flow is also more because the flow is divided into four separate rooms by the guide vane on the downstream side. But the width of the flow velocity that occurs on the inner walls of the downstream areas are shorter and smaller than the pathline the elbow without guide vane. In addition to providing positive role that break the existence of secondary flow as differences in the distribution of the inner and outer side.

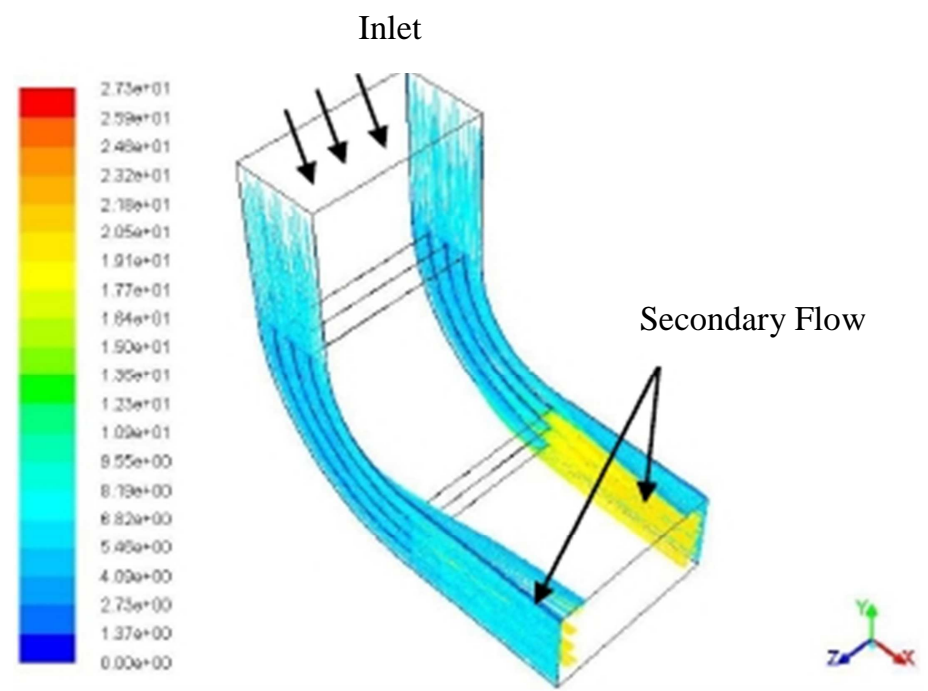

Figure 10. Pathline in wall elbow with three guide vanes

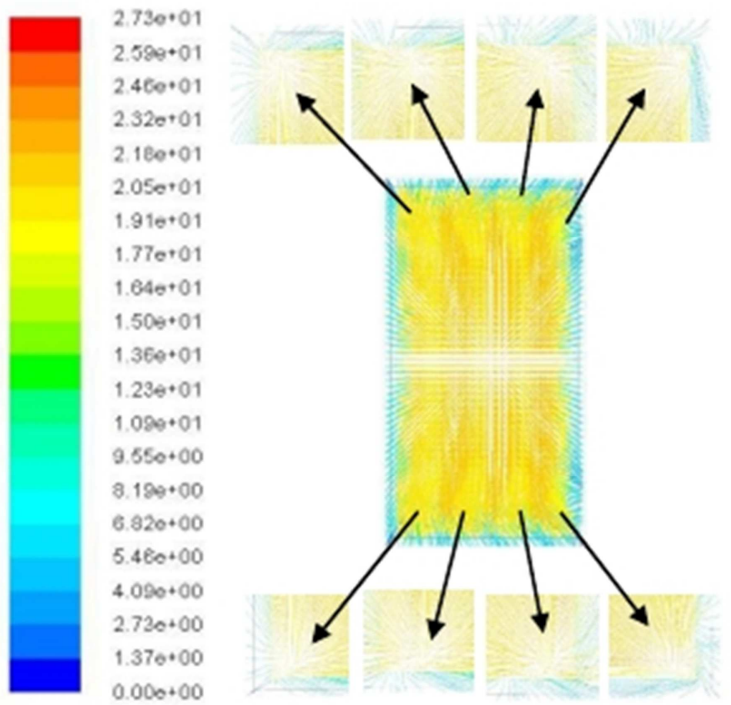

Figure 11. Vortex at outlet elbow with three guide vanes

Although with the addition of a guide vane breaker where secondary flow as the difference in the distribution of inner and outer sides, where the 
guide vane also have a negative effect on the vortex which propagate downstream side as shown by Figure 11. The existence of this vortex can result in blockage of the flow of the main flow, causing the value of greater pressure drop and reduced effective flow area.

\section{CONCLUSION}

From present experimental and numerical studies on the flow inside $90^{\circ}$ rectangular elbow without and with guide vanes can be drawn following the conclusion:

1. For rectangular elbow cross section with $\mathrm{Re}_{\mathrm{DH}} \approx 8.6 \times 10^{4}$ have generating pressure drop. Most small pressure drop indicated by the elbow without guide vane is $13.45 \mathrm{~Pa}$, whle large pressure drop indicated by the elbow with the insertion of three guide vanes is $30,31 \mathrm{~Pa}$. The insertion of three guide vanes can increase the pressure drop up to $235.14 \%$. This is because when the insertion number of guide vane it will also increase the skin friction between the fluid on the guide vanes.

2. The insertion guide vanes can make velocity distribution profile in outlet elbow can be returned to a uniform velocity profile. This occure in the insertion guide the twist flow on the downstream side after going through the elbow can be minimized.

3. Adding the number of guide vane is also making more vortex. Highest number of vortex occurs on three guide vanes but the addition of this vortex has a smaller vortex intensity.

This research also conclude that addition of guide vanes will contributing to make the flow become uniform again after through the elbow. More guide vanes will make more uniform flow which will be convenience for the fluid machinery works.

\section{REFERENCES}

[1] Cheng, D.Y., Laminar Flow Elbow System and Method, U.S. Patent Documents, No. 5,323,661, 1994

[2] Haskew, J.T., \& Sharif, M. A. R., Perfomance Evaluation of Vaned Pipe Bend in Turbulent Flow of Liquid Propellants, In Appl, Math. Modelling Vol 21, Elsevier Inc, 1997

[3] Kim, W.J. \& Patel, C., Influence of Streamwise Curvature on Longitudinal Vortices Imbeded in Turbulent Boundary Layers, J. Of Fluid Engineering, 123, pp. 211-218, 2001

[4] Miller, D.S., Internal flow systems, 2nd edition, BHRA (Information Service), 1990

[5] Sutardi, dkk., Experimental Study On The Effect of Guide Vane Insertion And Reynolds Numbers On The Flow Pressure Drop In A 900 Rectangular Elbow, jurusan teknik mesin, FTI-ITS, 2010 Taylor, E.S., "Secondary flow", National Commiter for Fluida Mechanics Films, 1968 
[6] Taylor, E.S., Secondary flow, National Commiter for Fluida Mechanics Films, 1968

[7] Williams, R. W., Computional Study of Duct and Pipe Flows Using The Method of Pseudo-Compressibility, AIAA Paper 91-1656, 1991 